\title{
Estudos sobre a toxicologia da $\varepsilon$-caprolactama
}

\author{
Marcus Vinicius Justo Bomfim, Shirley de Mello Pereira Abrantes, \\ Helena Pereira da Silva Zamith*
}

Instituto Nacional de Controle de Qualidade em Saúde, Fundação Oswaldo Cruz

\begin{abstract}
A ع-caprolactama (CAP) é um monômero precursor de polímeros denominados nylon 6 . Esses polímeros destinam-se à produção de tapetes, vestuário e materiais plásticos tais como equipamentos, sistemas e componentes automotivos, conectores, além de embalagens plásticas. Resíduos de CAP podem migrar de embalagens plásticas de nylon 6 para os alimentos. Diante disso, foi de interesse realizar uma revisão dos efeitos relativos à exposição à CAP e o seu impacto sobre a saúde humana. Estudos epidemiológicos indicam a possibilidade da CAP causar inflamações oculares e cutâneas, além de irritações no sistema respiratório. Pode ocorrer ainda hipotensão, taquicardia, palpitações, rinorréia, ressecamento nasal, efeitos geniturinários e sobre a reprodução como distúrbios nas funções menstrual e ovariana, e complicações no parto; além de problemas neurológicos e hematológicos. Estudos com animais são consistentes com tais relatos. Os estudos de genotoxicidade in vitro e in vivo por via oral e intraperitoneal mostram em sua grande maioria, resultados negativos, bem como ausência de efeitos carcinogênicos em ratos e camundongos e sobre o desenvolvimento e reprodução em ratos e coelhos.
\end{abstract}

Unitermos: Caprolactama/aspectos toxicológicos. Toxicodinâmica. Mutagenicidade. Carcinogenicidade. Embalagens plásticas/efeito tóxico.

$\varepsilon$-Caprolactam (CAP) is a precursor monomer of nylon 6 polymers. Nylon 6 is used in the manufacture of carpets, clothes and plastic materials, such as equipment, systems and automotive components, connectors and plastic packaging. CAP residues can migrate from nylon 6 plastic packaging to foods. Given this fact, this review was realized concerning the effects of CAP exposure and its impact on human health. Epidemiological studies indicate that CAP could cause ocular, cutaneous and respiratory irritations, as well as hypotension, tachycardia, palpitations, rhinorrhea, nose dryness, neurological and blood problems, and genitourinary and reproductive effects, such as alterations in ovarian-menstrual functions and pregnancy/birth complications. Animal studies are consistent with such reports; however, the majority of in vitro and in vivo genotoxicity studies by oral and intraperitoneal routes show negative results, including the absence of carcinogenicity in rats and mice and developmental and reproductive effects in rats and rabbits.

Uniterms: Caprolactam/toxicological aspects. Toxicodynamics. Mutagenicity. Carcinogenicity. Plastic packaging/toxic effects.

\section{INTRODUÇÃO}

A $\varepsilon$-caprolactama, azepan-2-ona (CAS 105-60-2), comumentemente denominada caprolactama (CAP), é uma amida-cíclica. O Quadro 1 (OECD, 2001) apresenta a fórmula estrutural da CAP e algumas de suas propriedades físico-químicas.

\footnotetext{
*Correspondência: H. P. S. Zamith. Departamento de Farmacologia e Toxicologia, Instituto Nacional de Controle de Qualidade em Saúde/FIOCRUZ, Av. Brasil, 4365 - Manguinhos - 21040-900 - Rio de Janeiro - RJ, Brasil. E-mail: helena.zamith@incqs.fiocruz.br
}

Em 1999, a União Européia produziu um volume aproximado de $1 \times 10^{6}$ de toneladas de CAP. Anualmente, a Ásia produz acima de $1 \times 10^{6}$ de toneladas e a América do Norte, entre $5 \times 10^{5}$ e $1 \times 10^{6}$ de toneladas da substância (OECD, 2001). A produção industrial baseia-se na reação química apresentada na Figura 1. A CAP é utilizada pela indústria química como precursor de polímeros denominados de poliamida 6 (comercialmente, conhecidos por nylon 6). O nylon 6 é um tipo de poliamida sintetizada a partir da polimerização de monômeros da CAP (Sarantópoulos, 2002). Em 2001, 73\% do nylon 6 produzido destinava-se, sob a forma de fibras, a 
QUADRO 1 - Fórmula estrutural e características físico-químicas da caprolactama

\begin{tabular}{|l|l|l|}
\hline \multicolumn{2}{|c|}{ Fórmula Estrutural } & \multicolumn{2}{|c|}{ Propriedades físico-químicas } \\
\hline \multirow{2}{*}{} & Peso Molecular & 113,16 \\
\hline & Ponto de Fusão & $69,2^{\circ} \mathrm{C}$ \\
\hline & Ponto de Ebulição & $270,8^{\circ} \mathrm{C}$ \\
\hline Densidade & $1,014 \mathrm{~g} / \mathrm{cm}^{3} \mathrm{a} 80^{\circ} \mathrm{C}$ \\
\hline & Pressão de Vapor & $0,13 \mathrm{~Pa}$ a $20^{\circ} \mathrm{C}$ \\
\hline & Coef. de partição & $0,12 \mathrm{a} 25^{\circ} \mathrm{C}$ \\
\hline & Solubilidade emágua & $4560 \mathrm{~g} / \mathrm{L} \mathrm{a} 20^{\circ} \mathrm{C}$ \\
\hline pH & $7-8,5$ \\
\hline & Solubilidade & $\begin{array}{l}\text { Água, etanol, benzeno, } \\
\text { clorofórmio, cicloexano }\end{array}$ \\
\hline
\end{tabular}

Fonte: Molecular Simulations, 1998 e OECD, 2001

fabricação de tapetes e vestuário, enquanto os $27 \%$ restantes, sob a forma de resinas, eram utilizados pela indústria para a produção de plásticos (equipamentos, sistemas e componentes automotivos, conectores, além de embalagens plásticas). As resinas ainda necessitam de tratamento prévio para consolidação do produto final. Para os equipamentos, sistemas e componentes automotivos, as resinas devem passar por um processo denominado de injeção. De outro modo, a resina deve sofrer um processo de extrusão para transformá-la em filmes ou filamentos que, agregados, darão origem à embalagem plástica (Koma, 2001).

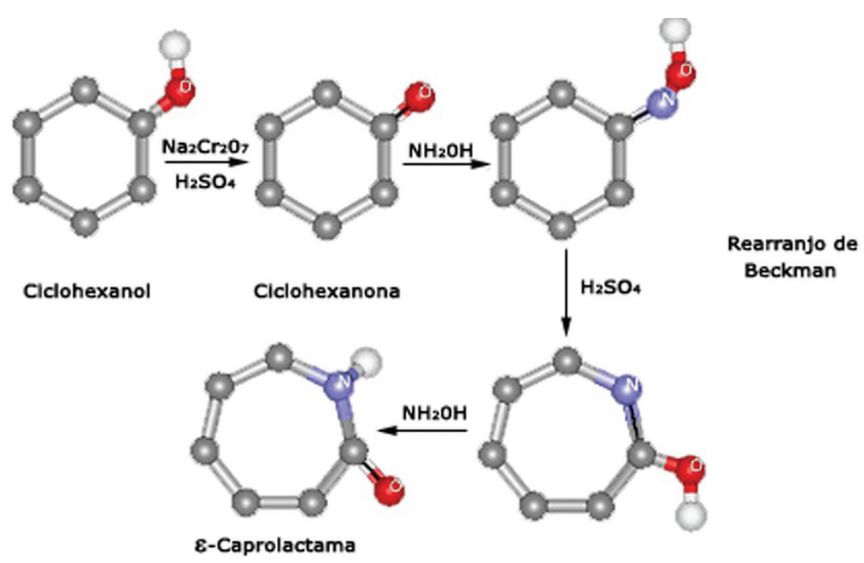

FIGURA 1 - Reação de obtenção da caprolactama (Molecular Simulations, 1998)

Ensaios de migração realizados no Instituto Nacional de Controle de Qualidade em Saúde (INCQS) com amostras de embalagens de nylon 6 destinadas a acondicionar mortadela, apresuntado, blanquet de peru e patês apresentaram em $37,5 \%$ das mesmas valores de migração de CAP superiores ao limite estabelecido em legislações brasileira e européia pertinentes (BRASIL,1999; CE,
2002). Ambas determinam como limite máximo de migração da CAP o valor de $15 \mathrm{mg} / \mathrm{kg}$ de alimento. Os resultados de migração obtidos variaram de 52 a 198 \% em relação ao referido limite.

Tais resultados suscitaram questionamentos quanto a repercussão de tais evidências à saúde humana e estimularam uma revisão bibliográfica da toxicologia da CAP, com a finalidade de se identificar os possíveis riscos de agravos à saúde, advindos de uma exposição à CAP.

A maior parte dos trabalhos científicos que tratam de aspectos toxicológicos associados à CAP são anteriores a 1997, concentrando-se na década de 80 , enquanto uma pequena parcela foi publicada após 1997. Isso poderia ser atribuído a fatores presentes no final dos anos $70 \mathrm{e}$ início dos 80 como a expansão da produção e consumo de produtos a base de nylon 6 (inicialmente no setor têxtil e, posteriormente, para outros segmentos) e avanços tecnológicos e científicos que permitiram e ampliaram a realização de estudos toxicológicos mais confiáveis e específicos. Sob o ponto de vista científico, a pesquisa relacionada à toxicologia da CAP foi limitada a partir da década de 90 pela realização, em períodos anteriores, de estudos , na sua maioria, conclusivos.

A localização dos artigos foi conduzida por meio de ferramentas de busca na rede internacional de computadores. Portais de pesquisa científica como Science Direct, Periódicos Capes, o sistema Toxnet de Medicina, o Micromedex Healthcare Series; e documentos relativos às posições da Environmental Protection Agency (EPA) e International Agency for Research on Cancer (IARC) com relação à CAP foram utilizados. Os artigos científicos não disponíveis na internet foram requisitados pelo Comut, com auxílio do Instituto Brasileiro de Informação em Ciência e Tecnologia que coordena o Catálogo Coletivo Nacional de Publicações Seriadas (CCN). 
Este trabalho de revisão da CAP aborda, principalmente, os aspectos toxicodinâmicos da CAP em humanos e animais experimentais decorrentes das exposições por vias cutânea, ocular e inalatória, a genotoxicidade in vitro e in vivo, a carcinogenicidade, bem como os efeitos sobre a reprodução e desenvolvimento dos animais.

\section{Aspectos toxicodinâmicos da CAP em humanos e animais experimentais}

\section{Efeitos em humanos}

A grande maioria dos estudos que tratam dos efeitos clínicos da CAP decorre de exposição ocupacional (Tabela I), porém alguns foram conduzidos com voluntários (Goldblatt et al., 1954; Aguirre et al., 1995; Ferguson, Wheeler, 1973). Em geral, são trabalhadores de indústrias químicas produtoras da CAP ou aquelas responsáveis pela transformação da CAP em fibras ou resinas de nylon 6 .

\section{Efeitos tóxicos decorrentes da exposição cutânea e ocular}

Em 1954, Goldblatt et al. aplicaram solução de 5\% de CAP em antebraços de 11 voluntários e somente 5 apresentaram sinais de irritação. Kelman (1986) observou efeitos como irritação, descamação e/ou fissura cutâneas em 8 trabalhadores expostos a níveis médios de $68 \mathrm{mg} / \mathrm{dm}^{3}$ de CAP sob a forma de poeira. Um trabalhador têxtil, manipulador de fibras de nylon, e com histórico de dermatite por contato ocupacional, foi submetido por Aguirre et al. (1995) ao teste tópico com solução aquosa de CAP 5\%. Observou-se eczema eritematoso difuso em pescoço, tórax e membros. Há também relatos de dermatite de contato e eczema, fissuras e hiperqueratose em trabalhadores expostos segundo EUA (2008). Em síntese, os estudos demonstram que a CAP pode ocasionar dermatite, irritação, descamação e/ou fissuras na pele, além de conjuntivite e queimaduras na córnea (Ferguson, Wheeler, 1973). Os efeitos podem se originar do contato direto ou da exposição ao vapor/poeira de CAP. Um fato que pode servir de alerta é que foram constatados consideráveis agravos à pele num trabalhador têxtil, manipulador de fibras de nylon (Aguirre et al., 1995). A princípio, a manipulação de fibras de nylon não representaria maiores preocupações, porém o trabalho indicou uma situação oposta.

\section{Efeitos tóxicos decorrentes da exposição por via inalatória}

Secura, rinorréia e produção de secreção no trato respiratório superior foram observadas em exposição aguda aos vapores de CAP em concentração de $61 \mathrm{mg} /$ $\mathrm{dm}^{3}$ (Hohensee, 1951). Voluntários apresentaram queima- ção no nariz e garganta quando expostos a partículas em suspensão ou ao vapor de CAP em concentrações iguais a $66 \mathrm{mg} / \mathrm{dm}^{3}$ (Ferguson, Wheeler, 1973). Irritação, tosse, sensibilização do sistema respiratório e broncoespasmo foram observados em trabalhadores expostos a partículas de CAP em suspensão ou vapor (Sittig, 1985; UNEP, 1985). Efeitos neurológicos e hematológicos agudos como crise convulsiva, febre e leucocitose foram relatados num trabalhador da indústria de nylon exposto durante três dias à CAP (Tuma et al., 1981). Os possíveis efeitos clínicos associados a exposição crônica à CAP podem ser visualizados na Tabela I. Existe um número razoável de estudos que tratam dos efeitos da inalação de vapor/poeira de CAP em humanos. No entanto, são confusos, pois a maioria são co-exposições, ou seja, de exposição a múltiplos compostos como nos trabalhos de Martynova et al. (1972) e Nadezhdina, Talakina (1971). As numerosas deficiências nos relatos, na apresentação dos dados e métodos, no número reduzido da amostra (Billmaier et al., 1992), na ausência de informações como duração de exposição (Liu et al., 1988) e níveis de exposição (Nadezhdina, Talakina, 1971), além de fatores não considerados, como os estilos de vida dos trabalhadores, impedem sua utilização em avaliações mais consistentes (EPA, 2008). A Environmental Protection Agency (EPA), inclusive, considera os estudos inadequados para o estabelecimento de uma concentração de referência para exposição crônica por via inalatória.

Um outro estudo que apresenta várias deficiências foi o desenvolvido por Ferguson e Wheeler (1973) que realizaram retrospectiva de exposições ocupacionais de 155 trabalhadores de duas plantas de produção de CAP, alguns com 17 anos de exposição, e outro de 5 trabalhadores voluntários expostos momentaneamente à CAP. Nesse último caso, a irritação de olhos, nariz e garganta foi transitória, cessando os efeitos após o término da exposição. Tais efeitos foram observados em concentrações de 100 ppm, reduzindo sua magnitude em concentrações inferiores a $25 \mathrm{ppm}$. Os autores sugerem que o desconforto percebido foi maior em trabalhadores de plantas do polímero do que nas indústrias do monômero, apesar da não mensuração do grau de desconforto apresentado pelos indivíduos. Sugeriu-se que a maior umidade na indústria do monômero protegeria os indivíduos de efeitos irritantes da CAP por promover a hidratação dos tecidos e depuração biológica. Na parte ocupacional do estudo, não foram declaradas a duração média de exposição, o número exato de expostos em cada planta, os dados históricos individuais e os níveis de CAP no ar, sendo todas as exposições determinadas por área e não por amostras aleatórias. A partir dessas constatações, não foi possível considerar o referido estudo como de duração crônica, uma vez que não foi 
TABELA I - Estudos sobre a toxicodinâmica da caprolactama após exposição de humanos por via inalatória

\begin{tabular}{|c|c|c|c|}
\hline $\begin{array}{l}\text { Período de } \\
\text { exposição }\end{array}$ & Órgãos/Sistemas & Efeitos clínicos relatados & Referência \\
\hline Crônica & $\begin{array}{l}\text { Geniturinário/ } \\
\text { Reprodutivo }\end{array}$ & $\begin{array}{l}\text { Distúrbios em funções ovarianas e menstruais em } 170 \text { gestantes } \\
\text { expostas à CAP ( } 37,1 \% \text { versus } 12,8 \% \text { do controle com } 101 \\
\text { gestantes). Os níveis não foram disponibilizados. }\end{array}$ & $\begin{array}{l}\text { Nadezhdina, } \\
\text { Talakina, } 1971\end{array}$ \\
\hline Crônica & Geniturinário & $\begin{array}{l}\text { Dismenorréia em } 300 \text { trabalhadoras e aumento de toxicose, parto } \\
\text { prematuro e hemorragias pós-natal em } 136 \text { trabalhadoras envolvidas } \\
\text { na produção de caprona (uma espécie de fibra têxtil que utiliza } \\
\text { nylon } 6 \text { para sua produção). Em ambos os casos, a concentração de } \\
\text { CAP excedeu em nove vezes o limite russo de } 10 \mathrm{mg} / \mathrm{m}^{3} \text { durante } \\
\text { nove anos. }\end{array}$ & $\begin{array}{l}\text { Martynova et al., } \\
1972\end{array}$ \\
\hline Crônica & $\begin{array}{l}\text { Geniturinário/ } \\
\text { Reprodutivo }\end{array}$ & $\begin{array}{l}\text { Disfunções no ciclo menstrual }(48,2 \%) \text { em } 300 \text { trabalhadoras de } \\
\text { indústria da CAP; e complicações na gestação e no parto em } 33,8 \% \\
\text { das gestantes expostas a CAP contra } 18,1 \% \text { de gestantes controle. }\end{array}$ & $\begin{array}{l}\text { Martynova et } \\
\text { al.,1972 }\end{array}$ \\
\hline Crônica & $\begin{array}{l}\text { Geniturinário/ } \\
\text { Reprodutivo }\end{array}$ & $\begin{array}{l}\text { Doenças inflamatórias do útero e anexos foram mais prevalentes em } \\
492 \text { trabalhadoras expostas a níveis inferiores a } 10 \mathrm{mg} / \mathrm{m}^{3} \text { de CAP e } \\
\text { bifenil em relação à população controle }(8,9 \% \text { contra } 1,08 \%) \text {. }\end{array}$ & Petrov, 1975 \\
\hline Não definida & $\begin{array}{l}\text { Geniturinário/ } \\
\text { Reprodutivo }\end{array}$ & $\begin{array}{l}\text { Menstruação irregular foi significativamente maior que nos controles } \\
\text { pareados }(34,3 \% \text { contra } 25 \%) \text { em coorte de } 304 \text { trabalhadoras } \\
\text { expostas a níveis inferiores a } 10 \mathrm{mg} / \mathrm{m}^{3} \text { de CAP. }\end{array}$ & Liu et al., 1988 \\
\hline Crônica & $\begin{array}{l}\text { Geniturinário/ } \\
\text { Reprodutivo }\end{array}$ & $\begin{array}{l}\text { Numa coorte de } 616 \text { trabalhadoras expostas a vários compostos, } \\
\text { incluindo CAP em concentrações inferiores a } 10 \mathrm{mg} / \mathrm{m}^{3} \text {, a incidência } \\
\text { de mioma uterino (um tumor de tecido muscular) foi } 2 \text { a } 3 \text { vezes } \\
\text { superior ao do grupo controle de } 182 \text { mulheres. }\end{array}$ & Angelov, 1988 \\
\hline Crônica & Nariz e Garganta & $\begin{array}{l}\text { Alterações distróficas das mucosas nasal e da garganta, além de } \\
\text { rinorréia e ressecamento da mucosa nasal. }\end{array}$ & UNEP, 1985 \\
\hline Crônica & Respiratório & $\begin{array}{l}\text { Avaliação da função respiratória (espirometria) em } 173 \text { trabalhadores } \\
\text { da indústria da CAP. Nenhuma diferença entre o grupo exposto e } \\
\text { o controle. }\end{array}$ & Patel, 1990 \\
\hline Crônica & Respiratório & $\begin{array}{l}\text { Não houve diferença significativa para testes de função pulmonar } \\
\text { em } 39 \text { trabalhadores de duas plantas, com exposição mínima de dez } \\
\text { anos a concentrações de CAP no ar de cerca de } 3,7 \mathrm{mg} / \mathrm{m}^{3} \mathrm{em} \text { uma } \\
\text { planta e de } 4,5 \text { e } 9,9 \mathrm{mg} / \mathrm{m}^{3} \text { de CAP, em outra planta. }\end{array}$ & Billmaier et al., 1992 \\
\hline Crônica & Respiratório & $\begin{array}{l}\text { Elevação da incidência de asma e bronquite em grupo de } \\
\text { trabalhadores expostos. }\end{array}$ & EUA, 2008 \\
\hline Crônica & Cardiovascular & $\begin{array}{l}\text { Desconforto no peito e palpitações com maior tendência a } \\
\text { desenvolver taquicardia e hipotensão média. Alterações no ECG: } \\
\text { bradicardia sinusal, disritmia sinusal, oscilação da onda P e } \\
\text { prolongação do intervalo PR. }\end{array}$ & EUA, 2008 \\
\hline
\end{tabular}

definida a população de trabalhadores e a duração média da exposição (EPA, 2008).

Os limites de exposição ocupacional à CAP recomendados por instituições norte americanas que regulamentam sobre segurança e medicina do trabalho, como a American Conference of Governmental Industrial Hygienists (AC$\mathrm{GIH}$ ) e National Institute of Occupational Safety and Health (NIOSH) são, respectivamente, $5 \mathrm{mg} / \mathrm{m}^{3}$ e $1 \mathrm{mg} / \mathrm{m}^{3}$ para vapor e poeira (ACGIH, 2003; NIOSH, 2007).

\section{Efeitos em animais}

\section{Efeitos tóxicos decorrentes de exposição cutânea e ocular}

Numa revisão de trabalhos russos organizada pelo Programa Ambiental das Nações Unidas (UNEP, 1985) concluiu-se que a CAP pode ocasionar irritação ocular e queimaduras na córnea em coelhos e sensibilização ou dermatite em cobaias. A irritação ocular ocorre a partir de 
concentrações de $10 \%$ de CAP, sendo que as concentrações entre 25 e $50 \%$ de CAP causam queimaduras na córnea.

Trabalho citado pela Organização para Cooperação Econômica e Desenvolvimento (OECD, 2001) contraria os resultados acima. A CAP não foi considerada sensibilizante em cobaias no teste de maximização (75\% CAP em água) e no teste modificado de Buehler (25\% de CAP em água) realizado de acordo com as diretrizes estabelecidas pelo Protocolo do Office of Prevention, Pesticides and Toxic Substances (OPPTS) 870.2600 da Agência de Proteção Ambiental Americana (EPA, 1998).

\section{Efeitos decorrentes de exposição por via inalatória}

A realização de estudos toxicológicos pela inalação de vapores de CAP torna-se quase impraticável devido à sua pressão de vapor extremamente baixa $\left(0,13 \mathrm{~Pa}\right.$ a $\left.20^{\circ} \mathrm{C}\right)$. Assim, historicamente, os estudos da CAP em animais decorrem, principalmente, da administração por via oral. No entanto, há relatos sobre possíveis efeitos nos sistemas respiratório, cardiovascular, geniturinário, hematológico e hepático decorrentes da exposição inalatória. Após exposição aguda por via inalatória, animais apresentaram hipotensão, hipertensão, hipoventilação (camundongos), hepatotoxicidade, lesões renais e danos sobre a espermatogênese (ACGIH, 1991; IARC, 1986; UNEP,1985 e EUA, 2008). Krichevskaya (1968) constatou também alterações na concentração sanguínea da colinesterase em ratos machos albinos (15/grupo) expostos durante 82 dias, a uma concentração máxima de vapor de CAP igual a $6,0 \mathrm{mg} / \mathrm{m}^{3}$. O significado desses resultados não está claro e poucas informações estão disponíveis, como o período de exposição (EPA, 2008). Não foram observadas alterações anátomo-patológicas ou evidências de mobilidade anormal em cobaias expostas a concentrações de CAP de
$51 \mathrm{mg} / \mathrm{m}^{3}$ durante 26 a 30 dias, porém observou-se leve irritação na mucosa nasal (Hohensee, 1951). Reinhold et al. (1998) avaliaram os efeitos de CAP em ratos SpragueDawley expostos, durante 91 dias, a 24, 70 e $243 \mathrm{mg} / \mathrm{m}^{3}$ (10 ratos/sexo). A queratinização da laringe foi observada nos animais tratados com a maior concentração estudada. Esses autores estabeleceram ainda, em ratos, um nível de efeito adverso não observado (NOAEL) de $70 \mathrm{mg} / \mathrm{m}^{3}$ para sistema respiratório superior e $243 \mathrm{mg} / \mathrm{m}^{3}$ para toxicidade sistêmica, neurotoxicidade e sistema respiratório inferior.

Em contrapartida, alguns trabalhos relatam a inexistência de quaisquer agravos às espécies testadas. Em estudo subagudo, cobaias foram expostas por $30 \mathrm{~min}$ durante 5 dias consecutivos a aerossóis de CAP em concentrações de 3,10 e $30 \mathrm{mg} / \mathrm{m}^{3}$, sendo monitoradas por pletismografia quanto à ocorrência de irritação, tosse, hipersensibilidade pulmonar e hipereatividade. Nenhum efeito foi observado (Alarie, Stock, 1990). No mesmo sentido, Lomonova (1966) não identificou qualquer efeito relacionado à exposição crônica de ratos albinos à CAP em concentrações de $10 \mathrm{mg} / \mathrm{m}^{3}$, quanto ao peso corpóreo, ao comportamento e a ocorrência de alterações clínicas e efeitos anátomo-patológicos.

\section{Estudos Genotóxicos in vitro}

Nas Tabelas II e III são apresentados os estudos referentes à mutagenicidade in vitro da CAP, respectivamente, em cepas de Salmonella typhimurium (teste de Ames) e em células de mamífero. A avaliação dos trabalhos foi conduzida tendo por base as diretrizes estabelecidas pela Organization for Economic Cooperation and Development (OECD) para testes de substâncias químicas.

TABELA II - Estudos de mutagenicidade da caprolactama em Salmonella typhimurium (Teste de Ames)

\begin{tabular}{|c|c|c|c|c|c|}
\hline Cepas & $\begin{array}{c}\text { Ativação } \\
\text { metabólica }\end{array}$ & Método & $\begin{array}{c}\text { Concentração } \\
(\mu \mathrm{g} / \text { placa })\end{array}$ & Resultado & Referência \\
\hline $\begin{array}{l}\text { TA97; TA98; } \\
\text { TA100; TA102 }\end{array}$ & $\begin{array}{c}-\mathrm{S} 9 /+\mathrm{S} 9 \\
\text { Aroclor } 1254\end{array}$ & Padrão & $32-1000$ & Negativo & Baker, Bonin, 1985 \\
\hline $\begin{array}{c}\text { TA98; TA100; } \\
\text { TA1535; TA1537; } \\
\text { TA1538 } \\
\end{array}$ & $\begin{array}{c}-\mathrm{S} 9 /+\mathrm{S} 9 \\
\text { Aroclor } 1254\end{array}$ & Padrão & $50-5000$ & Negativo & Rexroat, Probst, 1985 \\
\hline $\begin{array}{l}\text { TA97; TA98; } \\
\text { TA100; TA1535 }\end{array}$ & $\begin{array}{c}-\mathrm{S} 9 /+\mathrm{S} 9 \\
\text { Aroclor } 1254\end{array}$ & Pré-incubação & $100-10000$ & Negativo & Zeiger, Haworth, 1985 \\
\hline TA102 & $\begin{array}{c}+\mathrm{S} 9 \\
\text { Aroclor } 1254\end{array}$ & Padrão & $1-5000$ & Negativo & $\begin{array}{l}\text { Jung et. al., 1992; } \\
\text { Mueller et. al., } 1993\end{array}$ \\
\hline
\end{tabular}

Nota: Dados obtidos do Sistema de Informação de Pesquisa em Carcinogênese Química, base de dados da Livraria Nacional do Sistema TOXNET de Medicina (http://toxnet.nlm.nih.gov) 
TABELA III - Estudos in vitro de mutagenicidade da caprolactama em células de mamífero

\begin{tabular}{llllll}
\hline Ensaio & Células & $\begin{array}{l}\text { Ativação } \\
\text { metabólica }\end{array}$ & Concentração & Resultado & Referência \\
\hline Mutação gênica/TK & L5178Y & $\begin{array}{l}\text {-S9/+S9 } \\
\text { Aroclor 1254 }\end{array}$ & $1130-11320 \mu \mathrm{g} / \mathrm{mL}$ & Negativo & Amacher, Turner, 1985 \\
\hline $\begin{array}{l}\text { Mutação gênica/ } \\
\text { HPRT/6Tg }\end{array}$ & V79 & $-\mathrm{S} 9$ & $1-1000 \mu \mathrm{g} / \mathrm{mL}$ & Negativo & Kuroda et. al., 1985 \\
\hline $\begin{array}{l}\text { Mutação gênica/ } \\
\text { HPRT/6Tg }\end{array}$ & V79 & $\begin{array}{l}+ \text { S9 } \\
\text { (fenobarbital e } \\
\text { benzoflavona) }\end{array}$ & $32-1000 \mu \mathrm{g} / \mathrm{mL}$ & Negativo & Kuroda et. al., 1985 \\
& & & & \\
\hline
\end{tabular}

\begin{tabular}{|c|c|c|c|c|c|}
\hline $\begin{array}{l}\text { Mutação gênica/ } \\
\text { HPRT/6Tg }\end{array}$ & V79 & $-\mathrm{S} 9$ & $1000-4000 \mu \mathrm{g} / \mathrm{mL}$ & Negativo & Fox, Delow, 1985 \\
\hline $\begin{array}{l}\text { Mutação gênica/ } \\
\text { HPRT/6Tg }\end{array}$ & V79 & $\begin{array}{l}+ \text { S9 } \\
\text { (fenobarbital e } \\
\beta \text {-naftoflavona) }\end{array}$ & $300-3000 \mu \mathrm{g} / \mathrm{mL}$ & Negativo & Fox, Delow, 1985 \\
\hline
\end{tabular}

\begin{tabular}{llllll}
\hline UDS/ ${ }^{3} \mathrm{H}-\mathrm{TdR}$ & $\begin{array}{l}\text { Hepatócitos } \\
\text { de ratos }\end{array}$ & -S9 & $0,001-10 \mathrm{mM}$ & Negativo & Glauert et. al., 1985 \\
\hline $\begin{array}{l}\text { Mutação gênica/ } \\
\text { HPRT/6Tg }\end{array}$ & $\mathrm{CHO}$ & -CEH/+CEH & $1000-2000 \mu \mathrm{g} / \mathrm{mL}$ & Negativo & $\begin{array}{l}\text { Zdzienicka, Simmons, } \\
1985\end{array}$ \\
\hline $\begin{array}{l}\text { Mutação gênica/ } \\
\text { HPRT/Ouabaína }\end{array}$ & $\mathrm{CHO}$ & -CEH/+CEH & $1000-2000 \mu \mathrm{g} / \mathrm{mL}$ & Negativo & $\begin{array}{l}\text { Zdzienicka } \\
\text { Simmons, 1985 }\end{array}$ \\
\hline $\begin{array}{l}\text { Mutação gênica/ } \\
\text { HPRT/Ouabaína }\end{array}$ & $\mathrm{V79}$ & $+\mathrm{CEH}$ & $0,1-1 \mathrm{mM}$ & Negativo & Kuroki, Munakata, 1985 \\
\hline $\begin{array}{l}\text { Mutação gênica/ } \\
\text { HPRT/Ouabaína }\end{array}$ & $\mathrm{V79}$ & $\begin{array}{l}+ \text { S15 } \\
\text { (fenobarbital e } \\
\text { benzoflavona) }\end{array}$ & $0,1-1 \mathrm{mM}$ & Negativo & Kuroki, Munakata, 1985 \\
& & & & \\
\hline
\end{tabular}

\begin{tabular}{|c|c|c|c|c|c|}
\hline Mutação gênica/TK & L5178Y & $\begin{array}{l}\text {-S9/+S9 } \\
\text { Aroclor } 1254\end{array}$ & $500-10000 \mu \mathrm{g} / \mathrm{mL}$ & Negativo & Oberly et al., 1985 \\
\hline
\end{tabular}

\begin{tabular}{|c|c|c|c|c|c|}
\hline $\begin{array}{l}\text { Aberração } \\
\text { cromossômica }\end{array}$ & $\begin{array}{l}\text { Linfócitos } \\
\text { humanos }\end{array}$ & $\begin{array}{l}\text {-S9/+S9 } \\
\text { Aroclor } 1254\end{array}$ & $2500-10000 \mu \mathrm{g} / \mathrm{mL}$ & $\begin{array}{l}7500 \mu \mathrm{g} / \mathrm{mL}: \\
\text { Positivo }\end{array}$ & Kristiansen, Scott, 1989 \\
\hline $\begin{array}{l}\text { Aberração } \\
\text { cromossômica }\end{array}$ & $\begin{array}{l}\text { Linfócitos } \\
\text { humanos }\end{array}$ & $\begin{array}{l}\text {-S9/+S9 } \\
\text { Aroclor } 1254\end{array}$ & $550-5500 \mu \mathrm{g} / \mathrm{mL}$ & $\begin{array}{l}5500 \mu \mathrm{g} / \mathrm{mL}: \\
\text { Positivo }\end{array}$ & Sheldon, 1989b \\
\hline $\begin{array}{l}\text { Aberração } \\
\text { cromossômica }\end{array}$ & $\begin{array}{l}\text { Linfócitos } \\
\text { humanos }\end{array}$ & $\begin{array}{l}+ \text { S9 } \\
\text { Aroclor } 1254\end{array}$ & $25-400 \mathrm{mM}$ & $200 \mathrm{mM}$ : Positivo & $\begin{array}{l}\text { Norppa, Jarventaus, } \\
1989\end{array}$ \\
\hline $\begin{array}{l}\text { Aberração } \\
\text { cromossômica }\end{array}$ & $\begin{array}{l}\text { Linfócitos } \\
\text { humanos }\end{array}$ & $-\mathrm{S} 9$ & $12,5-100 \mathrm{mM}$ & $50 \mathrm{mM}$ : Positivo & $\begin{array}{l}\text { Norppa, Jarventaus, } \\
1989\end{array}$ \\
\hline $\begin{array}{l}\text { Troca entre } \\
\text { cromátides-irmãs }\end{array}$ & $\mathrm{CHO}$ & $\begin{array}{l}\text {-S9/+S9 } \\
\text { Aroclor } 1254\end{array}$ & $15,6-250 \mathrm{mM}$ & $\begin{array}{l}125 \mathrm{mM}(+\mathrm{S} 9) \text { : } \\
\text { Positivo } \\
\text {-S9: Negativo }\end{array}$ & $\begin{array}{l}\text { Norppa, Jarventaus, } \\
1989\end{array}$ \\
\hline
\end{tabular}

Nota: Dados obtidos do Sistema de Informação de Pesquisa em Carcinogênese Química, base de dados da Livraria Nacional do Sistema TOXNET de Medicina (http://toxnet.nlm.nih.gov); UDS: Síntese de DNA não programada; CEH: Células embrionárias de hamster; TK: Timidina-quinase; HPRT: Hipoxantina-guanina fosforibosil transferase; 6Tg: 6-Tioguanina; ${ }^{3} \mathrm{H}-\mathrm{Tdr}$ : Timidina tritiada; L5178Y: Células de linfoma de camundongo; CHO: Células de ovário de hamster chinês; V79: Células de pulmão de hamster chinês. 
O teste de mutação reversa de Ames emprega linhagens de Salmonella typhimurium auxotróficas para histidina (his-), apresentando mutações no operon desse aminoácido o que não as torna capazes de crescer em meio de cultura mínimo, sem histidina. Tais linhagens foram construídas para detectar mutações no operon histidina, do tipo deslocamente do quadro de leitura (TA98, TA1537 ou TA97 e TA1538), de substituição de pares de base (TA1535) e de ambos os tipos (TA100). A TA102 detecta mutágenos intercalantes. O ensaio baseia-se na capacidade das células bacterianas de reverterem mutações e restabelecer a funcionalidade de síntese de histidina. A CAP apresentou resultados negativos em todas as linhagens testadas, pelos métodos padrão e de pré-incubação, na ausência e presença de ativação metabólica (mistura S9) estando de acordo com as diretrizes estabelecidas pelo Protocolo 471 (OECD, 1997). Apesar da concentração máxima de $5000 \mu \mathrm{g}$ de CAP / placa não ter sido testada (Baker, Bonin, 1985) pelo método padrão, concentração de até $10000 \mu \mathrm{g}$ de CAP/placa através da pré-incubação foi avaliada apresentando resultados negativos (Zeiger, Haworth,1985). A Tabela III mostra os resultados dos ensaios in vitro de mutagenicidade/genotoxicidade da CAP em células V79, CHO, L5178Y, linfócitos humanos e em hepatócitos de ratos para detecção de mutações gênicas e cromossômicas, bem como de trocas recíprocas de DNA entre cromátides irmãs e de síntese de DNA não programada (UDS). A CAP apresentou resultados negativos nos ensaios UDS (Protocolo 482, OECD, 1986), CHO e V79/HPRT e L5178Y/TK (Amacher, Turner, 1985; Oberly et al., 1985), mesmo quando testada em concentrações acima da concentração limite recomendada de $5000 \mu \mathrm{g} / \mathrm{mL}$ (Protocolo 476, OECD, 1997), na ausência e na presença de diferentes sistemas de ativação metabólica S9 de fígado de rato induzido por Aroclor 1254 e fenobarbital/ $\beta$-naftoflavona e CEH. Quanto aos ensaios de aberrações cromossômicas em linfócitos humanos e de trocas entre cromátides irmãs em células $\mathrm{CHO}$, a CAP somente causou resultados positivos não relevantes em concentrações acima de $5000 \mu \mathrm{g} / \mathrm{mL}$ ou 10 $\mathrm{mM}$ recomendadas pela OECD (Protocolos 473, 1997; 479, 1986). Segundo Ashby, Shelby (1989), a maioria desses resultados parece estar associada a erros técnicos aleatórios, pois os efeitos foram geralmente fracos e não reprodutíveis em estudos intra ou interlaboratoriais utilizando o mesmo sistema teste.

\section{Estudos Genotóxicos in vivo}

Os testes de recombinação e mutação somática (SMART) e de recessivo letal ligado ao sexo (SLRL) conduzidos por Vogel (1989) em Drosophila melanogaster mostraram que a CAP induziu respectivamente, mutações em células somáticas e alterações nos estágios iniciais das células germinais, porém não causou mutações nas células germinais do inseto. Quando comparado ao SMART, o ensaio SLRL (Protocolo 477 da OECD, 1984) tem uma maior relevância, pois permite a detecção de mutações recessivas letais em cerca de 880 diferentes locus no cromossomo X o que representa aproximadamente a $80 \%$ de todo cromosomo $\mathrm{X}$, que, por sua vez, corresponde a cerca de $1 / 5$ do genoma total do inseto. Tanto a OECD quanto a EPA não disponibilizam diretrizes para o teste SMART.

No ensaio de micronúcleo em células de medula óssea, a CAP, quando administrada pelas vias oral (Sheldon, 1989a) e intraperitoneal (Ishidate, Odagiri, 1989) a duas diferentes cepas de camundongos não induziu dano cromossômico e ao aparelho mitótico dos eritroblastos. Baseado no Protocolo 474 (OECD, 1997), o número recomendado de células policromáticas micronucleadas a ser analisado é de, no mínimo, 2000 células, sendo os resultados negativos obtidos por Sheldon (1989a) em ambos os sexos mais consistentes do que os obtidos por Ishidate, Odagiri (1989).

A CAP, por via intraperitoneal, não induziu trocas entre cromátides irmãs e aberrações cromossômicas em células de medula óssea de camundongos B6C3F1 machos (Mcfee, Lowe, 1989) estando o ensaio de aberrações cromossômicas, em termos gerais, de acordo com as diretrizes estabelecidas pela OECD (Protocolo 475, 1997). A OECD não disponibiliza diretrizes para o ensaio in vivo de trocas entre cromátides irmãs, porém, de acordo com as recomendações da EPA (Protocolo OPPTS 870.5915, 1996) a restrição ao trabalho encontra-se na utilização de apenas um sexo e no fato do número de animais ter sido inferior a 5 por grupo. Apesar da diretiva ser flexível e admitir tal delineamento em caso de justificativa, o artigo não a apresentou estando o trabalho, desta forma em desacordo com o recomendado.

O Protocolo 486 (OECD, 1997) recomenda que os testes UDS in vivo em células hepáticas, principalmente de ratos, sejam realizados em ambos os sexos, com 3 animais por grupo e com pelo menos 2 níveis de dose administradas preferencialmente por via oral. Salienta-se que a utilização de ambos os sexos pode ser ignorada se houver dados disponíveis que comprovem a equivalência de efeito entre os sexos para as espécies e vias de exposição a serem estudadas. O estudo desenvolvido por Working (1989) utilizou espermatócitos, ao invés de hepatócitos de ratos. Não há guias na OECD ou EPA para ensaios UDS em células diferentes de hepatócitos. Em contraposição ao sugerido pela OECD, Bermudez et al. (1989) avaliaram 
somente uma dose de CAP por via oral (750 mg/kg). Já Parodi et al. (1989) confirmaram os resultados negativos quanto à genotoxicidade da $\mathrm{CAP}$ em hepatócitos de ratos obtidos por Bermudez et al. (1989). Parodi et al.(1989) analisaram a fragmentação do DNA em hepatócitos de ratos e camundongos, após administração via intraperitoneal de dose única de CAP $(580 \mathrm{mg} / \mathrm{kg})$, por três diferentes métodos. Os ensaios realizados pelo método viscométrico e fluorométrico (considerados pelos autores mais consistentes) apresentaram resultados negativos. Somente os resultados obtidos a partir da eluição alcalina mostraram que a CAP pode ocasionar alterações na conformação da dupla hélice do DNA, não relacionada a qualquer dano no mesmo (Parodi et al., 1989). A OECD e a EPA não disponibilizam guias para o ensaio de medida de fragmentação de DNA mencionado acima.

A OECD (Protocolo 484, 1986) recomenda que o spot test em camundongos para a detecção in vivo de mutações somáticas em células fetais seja realizado, empregando, pelo menos, dois níveis de dose de até $1000 \mathrm{mg} /$ $\mathrm{kg}$ para substâncias relativamente não tóxicas. Caso não seja possível, a maior dose praticável deve ser utilizada. Sob esta ótica, os resultados de Fahrig (1989) e de Fahrig, Klauss (1989) são relevantes, pois estão de acordo com o protocolo disponibilizado pela OECD.

Friedman, Salerno (1980) avaliaram em ratos F344 os efeitos decorrentes da administração por via oral, de dose única de CAP $(1500 \mathrm{mg} / \mathrm{kg})$ sobre o metabolismo de aminoácidos, através da determinação das atividades enzimáticas da tirosina aminotransferase (TAT) e da triptofano-oxigenase (TFO). A estrutura da CAP sugere que a partir de sua hidrólise in vivo se forme o ácido aminocapróico, também ingerido pelos animais através da dieta (1 a $5 \%$ ). É esperado que essa substância modifique as vias metabólicas normais, pois o aumento de aminoácidos não-essenciais e de amino-compostos podem ocasionar alterações nas vias de síntese e de degradação. Assim, a alta ingestão do aminoácido poderia causar desequilíbrio ou ocasionar toxicidade que, eventualmente, pudesse estar relacionada a estas alterações bioquímicas. Os autores desconsideraram a possibilidade de que o aumento na indução de ambas enzimas pela CAP estivesse associado ao dano do DNA ou na atividade da RNA polimerase, pois a indução permaneceu mesmo após a administração de actinomicina $\mathrm{D}$, bloqueadora da RNA polimerase. Os autores ainda chamam a atenção para o fato de haver redução dessa resposta para o tratamento em doses repetidas e sugerem estudos adicionais. A OECD e a EPA não disponibilizam protocolo para este ensaio.

Os resultados dos estudos de genotoxicidade da CAP, realizados in vivo, são sintetizados na Tabela IV.

\section{Carcinogenicidade}

O estudo de carcinogenicidade considerado referência em relação à exposição oral à CAP foi o desenvolvido pelo National Toxicology Program (EUA, 1982), órgão ligado ao governo americano. Na Tabela V constam, além da carcinogenicidade, os resultados dos ensaios de toxicidade aguda, subaguda e subcrônica previamente realizados com ratos $\mathrm{F} 344$ e com camundongos B6C3F1 para definição das doses empregadas nos ensaios de carcinogenicidade. O estudo (EUA, 1982) é consistente com os resultados apresentados por Serota et al. (1988) no que se refere à redução do peso corporal médio e de consumo de ração dos animais. Nenhum efeito carcinogênico foi constatado. $\mathrm{O}$ estudo atendeu a todas as recomendações estabelecidas pelo Protocolo 451 (OECD, 1981). Adicionalmente, a Agência Internacional de Pesquisa sobre Câncer (IARC), através da Monografia de Avaliação dos Riscos Carcinogênicos para Humanos, no caso específico da CAP, menciona que não existem dados epidemiológicos relevantes quanto à carcinogenicidade da $\mathrm{CAP}$ e que há evidências sugerindo ausência de atividade carcinogênica em animais experimentais. A inexistência de dados epidemiológicos consistentes em humanos levou a IARC a classificar a CAP como provavelmente não carcinogênica (IARC, 1999).

\section{Efeitos sobre a reprodução e desenvolvimento de animais}

Os trabalhos que tratam dos possíveis efeitos da CAP sobre o desenvolvimento e reprodução apresentaram resultados coerentes. Durante a gestação, Gad et al. (1987) trataram por via oral, ratos F344 (20/grupo experimental), com 3 doses de CAP $(100,500$ e $1000 \mathrm{mg} / \mathrm{kg}$ de peso corpóreo) e coelhos Nova Zelândia (20/grupo), com doses de 50,150 e $250 \mathrm{mg} / \mathrm{kg}$ peso corpóreo. Não foram observados efeitos embriotóxicos ou teratogênicos. Baseado no Protocolo 414 referente à toxicidade de desenvolvimento pré-natal (OECD, 2001), o estudo realizado por Gad et al. (1987) não apresenta qualquer limitação. Já Serota et al. (1988) realizaram um estudo mais abrangente de reprodução em três gerações, por via oral, também em ratos F344 (10 machos e 20 fêmeas/grupo), no qual analisaram diversos parâmetros, tais como, mortalidade, sinais clínicos, desempenho reprodutivo e alterações anátomo-patológicas, especialmente dos órgãos do sistema reprodutivo. O estudo não constatou quaisquer alterações clínicas, anátomo-patológicas, bem como, em índices de fertilidade/gestação, de sobrevivência da prole, no número de nascidos vivos e filhotes por ninhada em ratos F344 de 
TABELA IV - Estudos da genotoxicidade in vivo da caprolactama

\begin{tabular}{|c|c|c|c|c|c|c|c|}
\hline Ensaio & Espécie & Células & Grupos $\left(n^{\circ}\right.$, sexo $)$ & Via de exposição & Doses & Efeitos & Referência \\
\hline $\begin{array}{l}\text { Micronúcleo em } \\
\text { eritrócitos }\end{array}$ & $\begin{array}{l}\text { Camundongos } \\
\text { C57BL/6J }\end{array}$ & Medula óssea & $\begin{array}{l}5 \text { machos e } 5 \\
\text { fêmeas/grupo }\end{array}$ & Oral (dose única) & $435 ; 700 \mathrm{mg} / \mathrm{kg}$ & $\begin{array}{l}700 \mathrm{mg} / \mathrm{kg}(1000 \\
\text { células analisadas): } \\
\text { Positivo (5000 } \\
\text { células analisadas): } \\
\text { Negativo }\end{array}$ & Sheldon, 1989a \\
\hline $\begin{array}{l}\text { Micronúcleo em } \\
\text { eritrócitos }\end{array}$ & $\begin{array}{l}\text { Camundongos } \\
\text { ICR/JCL }\end{array}$ & Medula óssea & 5 machos/grupo & $\begin{array}{l}\text { Intraperitoneal } \\
\text { (dose única) }\end{array}$ & $\begin{array}{l}125 ; 250 ; \\
500 \mathrm{mg} / \mathrm{kg}\end{array}$ & $\begin{array}{l}1000 \text { células } \\
\text { analisadas: } \\
\text { Negativo }\end{array}$ & $\begin{array}{l}\text { Ishidate, Odagiri, } \\
1989\end{array}$ \\
\hline $\begin{array}{l}\text { Trocas entre } \\
\text { cromátides-irmãs } \\
\text { (SCE) e aberração } \\
\text { cromossômica(AC) }\end{array}$ & $\begin{array}{l}\text { Camundongos } \\
\text { B6C3F1 }\end{array}$ & Medula óssea & $\begin{array}{l}\text { SCE: } 4 \text { machos/ } \\
\text { grupo } \\
\text { AC.: } 8 \text { machos/ } \\
\text { grupo }\end{array}$ & $\begin{array}{l}\text { Intraperitoneal } \\
\text { (dose única) }\end{array}$ & $\begin{array}{l}175 ; 350 ; \\
700 \mathrm{mg} / \mathrm{kg}\end{array}$ & $\begin{array}{l}\text { Ausência de } \\
\text { indução de SCE } \\
\text { e AC. }\end{array}$ & Mcfee, Lowe, 1989 \\
\hline UDS & Ratos F344 & Hepatócitos & $\begin{array}{l}3 \text { machos/tempo } \\
12 ; 24 \text { e } 48 \mathrm{~h}\end{array}$ & Oral (dose única) & $750 \mathrm{mg} / \mathrm{kg}$ & $\begin{array}{l}\text { Ausência de } \\
\text { indução de dano } \\
\text { ao DNA. }\end{array}$ & $\begin{array}{l}\text { Bermudez et al., } \\
1989\end{array}$ \\
\hline UDS & Ratos F344 & Espermatócitos & $\begin{array}{l}3 \text { machos/tempo } \\
12 ; 24 \mathrm{e} 48 \mathrm{~h}\end{array}$ & Oral (dose única) & $750 \mathrm{mg} / \mathrm{kg}$ & $\begin{array}{l}\text { Ausência de } \\
\text { indução de dano } \\
\text { ao DNA em } \\
\text { espermatócitos no } \\
\text { paquiteno }\end{array}$ & Working, 1989 \\
\hline $\begin{array}{l}\text { Spot test } \mathrm{em} \\
\text { camundongo }\end{array}$ & $\begin{array}{l}\text { Camundongos } \\
\text { C57/B1XT }\end{array}$ & Melanoblastos & $\begin{array}{l}\text { Fêmeas: Mínimo } \\
\text { 95/grupo }\end{array}$ & $\begin{array}{l}\text { Intraperitoneal } \\
\text { (dose única) }\end{array}$ & $400 ; 500 \mathrm{mg} / \mathrm{kg}$ & $\begin{array}{l}\text { Indução de } \\
\text { mutações e de } \\
\text { possível efeito } \\
\text { recombinogênico }\end{array}$ & $\begin{array}{l}\text { Fahrig, } \\
\text { 1989;Fahrig, } \\
\text { Klauss, } 1989\end{array}$ \\
\hline $\begin{array}{l}\text { Fragmentação } \\
\text { de DNA: eluição } \\
\text { alcalina }\end{array}$ & $\begin{array}{l}\text { Ratos Sprague- } \\
\text { Dawley }\end{array}$ & Hepatócitos & 3 machos/grupo & $\begin{array}{l}\text { Intraperitoneal } \\
\text { (dose única) }\end{array}$ & $580 \mathrm{mg} / \mathrm{kg}$ & $\begin{array}{l}\text { Negativo com } \\
\text { alteração da } \\
\text { conformação do } \\
\text { DNA }\end{array}$ & Parodi et al., 1989 \\
\hline $\begin{array}{l}\text { Fragmentação } \\
\text { de DNA: eluição } \\
\text { alcalina }\end{array}$ & $\begin{array}{l}\text { Camundongos } \\
\text { CD-I Swiss }\end{array}$ & Hepatócitos & 5 machos/grupo & $\begin{array}{l}\text { Intraperitoneal } \\
\text { (dose única) }\end{array}$ & $580 \mathrm{mg} / \mathrm{kg}$ & $\begin{array}{l}\text { Negativo com } \\
\text { alteração da } \\
\text { conformação do } \\
\text { DNA }\end{array}$ & Parodi et al., 1989 \\
\hline SMART & $\begin{array}{l}\text { Drosophila } \\
\text { melanogaster }\end{array}$ & Células somáticas & $\begin{array}{l}\text { Fêmeas: Mínimo } \\
406 \text { olhos testados/ } \\
\text { grupo }\end{array}$ & Oral & $\begin{array}{l}2,5 ; 5,0 ; 10 ; \\
20 \mathrm{mM}\end{array}$ & $\begin{array}{l}\text { 5; 10; } 20 \mathrm{mM}: \\
\text { Clastogênica }\end{array}$ & Vogel, 1989 \\
\hline SLRL & $\begin{array}{l}\text { Drosophila } \\
\text { melanogaster }\end{array}$ & Células germinais & $\begin{array}{l}\text { Machos e fêmeas: } \\
\text { Mínimo de } 88 / \\
\text { grupo }\end{array}$ & Oral & $\begin{array}{l}2,5 ; 5,0 ; 10 \\
20 \mathrm{mM}\end{array}$ & $\begin{array}{l}\text { Fêmeas: } \\
\text { Clastogênica } \\
\text { Machos: Não } \\
\text { clastogênica }\end{array}$ & Vogel, 1989 \\
\hline
\end{tabular}

Notas: UDS: Síntese de DNA não programada; SMART: Teste de recombinação e de mutação somática em Drosophila melanogaster; SLRL: Teste recessivo letal ligado ao sexo em Drosophila melanogaster.

ambos os sexos expostos à dose de 1000 ppm de CAP na ração, equivalente à dose diária estimada de $50 \mathrm{mg} / \mathrm{kg}$ de peso corpóreo. Entretanto as doses de 5000 e 10000 ppm de CAP na ração, correspondentes a cerca de 250 e 500 $\mathrm{mg} / \mathrm{kg}$ de peso corpóreo, causaram redução no ganho de peso corpóreo e no consumo de ração, principalmente, em animais da $2^{\mathrm{a}}$ e $3^{\mathrm{a}}$ gerações Adicionalmente, na dose de 10000 ppm ocorreu um leve aumento de nefropatias espontâneas em machos da $1^{\mathrm{a}}$ geração. Cabe salientar que a OECD disponibiliza diretrizes para estudos sobre reprodução e desenvolvimento, porém nenhum que se enquadre perfeitamente nos experimentos realizados por Serota et al. (1988). A OECD oferece os Protocolos 415 de 1983 e 416 de 2001 para o tipo de ensaio desenvolvido por Serota et al. (1988), referentes, respectivamente, aos estudos de toxicidade reprodutiva em uma e duas gerações. 
TABELA V - Estudos toxicológicos in vivo da caprolactama desenvolvidos pelo National Toxicology Program (EUA, 1982)

\begin{tabular}{|c|c|c|c|c|c|c|}
\hline Ensaio & Espécie & Parâmetros & $\begin{array}{l}\text { Grupos } \\
\left(n^{\circ}, \operatorname{sexo}\right)\end{array}$ & $\begin{array}{l}\text { Via e duração } \\
\text { de exposição }\end{array}$ & $\begin{array}{l}\text { Doses } \\
(\mathrm{mg} / \mathrm{kg})\end{array}$ & Efeitos \\
\hline Toxicidade aguda & Ratos F344 & Mortalidade & $\begin{array}{l}5 \text { machos e } \\
\text { fêmeas/grupo }\end{array}$ & $\begin{array}{l}\text { Gavagem } \\
\text { (dose única) }\end{array}$ & $\begin{array}{l}681 ; 1000 ; \\
1470 ; 2150 ; \\
3160\end{array}$ & 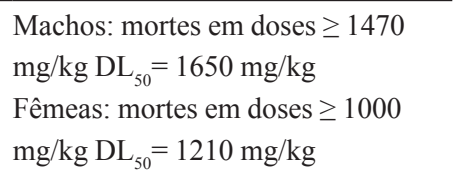 \\
\hline Toxicidade aguda & $\begin{array}{l}\text { Camundongos } \\
\text { B6C3F1 }\end{array}$ & Mortalidade & $\begin{array}{l}5 \text { machos e } \\
\text { fêmeas/grupo }\end{array}$ & $\begin{array}{l}\text { Gavagem } \\
\text { (dose única) }\end{array}$ & $\begin{array}{l}1000 ; 1470 \\
2150 ; 3160 \\
4640\end{array}$ & $\begin{array}{l}\text { Machos e fêmeas: mortes em doses } \\
\geq 2150 \mathrm{mg} / \mathrm{kg} \\
\text { Machos: } \mathrm{DL}_{50}=2070 \mathrm{mg} / \mathrm{kg} \\
\text { Fêmeas: } \mathrm{DL}_{50}=2490 \mathrm{mg} / \mathrm{kg}\end{array}$ \\
\hline $\begin{array}{l}\text { Toxicidade } \\
\text { Subaguda }\end{array}$ & $\begin{array}{l}\text { Ratos F344 e } \\
\text { Camundongos } \\
\text { B6C3F1 }\end{array}$ & $\begin{array}{l}\text { Mortalidade, } \\
\text { sinais clínicos e } \\
\text { alterações anátomo- } \\
\text { patológicas }\end{array}$ & $\begin{array}{l}5 \text { machos e } \\
\text { fêmeas/grupo }\end{array}$ & $\begin{array}{l}\text { Oral } \\
\text { (14 dias) }\end{array}$ & $\begin{array}{l}5000 ; 10000 ; \\
15000 ; 20000 \\
30000^{*}\end{array}$ & $\begin{array}{l}\text { Observou-se palidez e manchas nos } \\
\text { rins de ratos machos em todas as } \\
\text { doses ( } 60 \text { a } 100 \% \text { de incidência). } \\
5000 \text { ppm: morte de } 1 \text { rato macho }\end{array}$ \\
\hline $\begin{array}{l}\text { Toxicidade } \\
\text { Subcrônica }\end{array}$ & Ratos F344 & $\begin{array}{l}\text { Mortalidade, } \\
\text { sinais clínicos e } \\
\text { alterações anátomo- } \\
\text { patológicas }\end{array}$ & $\begin{array}{l}12 \text { machos e } \\
\text { fêmeas/grupo }\end{array}$ & $\begin{array}{l}\text { Oral } \\
\text { (90 dias) }\end{array}$ & $\begin{array}{l}625 ; 1250 ; \\
2500 ; 5000 ; \\
7500^{*}\end{array}$ & $\begin{array}{l}\text { Ausência de mortalidade e alterações } \\
\text { anátomo-patológicas. Redução no } \\
\text { ganho de peso em torno de } 13 \% \text {, não } \\
\text { dose- dependente. } \\
7500 \text { ppm: redução do consumo de } \\
\text { ração em torno de } 21 \% \text {. }\end{array}$ \\
\hline
\end{tabular}

\begin{tabular}{|c|c|c|c|c|c|c|}
\hline $\begin{array}{l}\text { Toxicidade } \\
\text { Subcrônica }\end{array}$ & $\begin{array}{l}\text { Camundongos } \\
\text { B6C3F1 }\end{array}$ & $\begin{array}{l}\text { Mortalidade, } \\
\text { sinais clínicos e } \\
\text { alterações anátomo- } \\
\text { patológicas }\end{array}$ & $\begin{array}{l}10 \text { machos e } \\
\text { fêmeas/grupo }\end{array}$ & $\begin{array}{l}\text { Oral } \\
\text { (90 dias) }\end{array}$ & $\begin{array}{l}5000 ; 10000 \\
15000 ; 20000 \\
30000 *\end{array}$ & $\begin{array}{l}\text { Ausência de alterações anátomo- } \\
\text { patológicas. } \\
\text { Fêmeas: } 2 \text { mortes em dose de } 30000 \\
\text { ppm. } \\
\text { Machos: redução ( } 36 \% \text { ) no ganho de } \\
\text { peso para todas as doses, não dose- } \\
\text { dependente. } \\
\text { Fêmeas: redução no ganho de } \\
\text { peso para todas as doses, dose- } \\
\text { dependente. }\end{array}$ \\
\hline Carcinogenicidade & Ratos F344 & $\begin{array}{l}\text { Alterações anátomo- } \\
\text { patológicas }\end{array}$ & $\begin{array}{l}50 \text { machos e } \\
\text { fêmeas/grupo }\end{array}$ & $\begin{array}{l}\text { Oral } \\
\text { (720 dias) }\end{array}$ & $3750 ; 7500 *$ & $\begin{array}{l}\text { Negativo, porém apresentou ganho } \\
\text { de peso inferior ao controle em } \\
\text { ambas as doses. }\end{array}$ \\
\hline Carcinogenicidade & $\begin{array}{l}\text { Camundongos } \\
\text { B6C3F1 }\end{array}$ & $\begin{array}{l}\text { Alterações anátomo- } \\
\text { patológicas }\end{array}$ & $\begin{array}{l}50 \text { machos e } \\
\text { fêmeas/grupo }\end{array}$ & $\begin{array}{l}\text { Oral } \\
\text { (720 dias) }\end{array}$ & $7500 ; 15000 *$ & $\begin{array}{l}\text { Negativo, porém apresentou ganho } \\
\text { de peso inferior ao controle em } \\
\text { ambas as doses. }\end{array}$ \\
\hline
\end{tabular}

Nota: (*) Doses de CAP em ppm na ração

A despeito disso, o Protocolo 416, foi utilizado na análise do estudo de Serota et al.(1988). Este estudo encontra-se de acordo com as diretrizes da OECD (2001).

\section{CONSIDERAÇÕES FINAIS}

Os estudos em animais confirmaram efeitos cutâneos e oculares descritos em humanos a partir do contato direto ou pela exposição aos vapores ou poeira da CAP. Tais efeitos são caracterizados por sinais de dermatite, eczema, fissuras e/ou descamação da pele bem como conjuntivite e queimaduras da córnea.

Embora existam inúmeras deficiências e problemas nos relatos epidemiológicos, há uma sinalização de que a CAP possa causar em humanos, irritação no nariz e garganta, asma, broncoespasmo e tosse quando expostos 
a concentrações aproximadas de $61 \mathrm{mg} / \mathrm{dm}^{3}$ no ar. Podem ocorrer ainda rinorréia, ressecamento nasal, hipotensão, taquicardia, palpitações, alterações no ciclo menstrual, complicações no parto, além de convulsão e leucocitose. Estudos em ratos apontam para efeitos similares àqueles relatados em humanos. Kerr et al.(1976) relataram convulsões em ratos expostos à doses superiores a $600 \mathrm{mg} / \mathrm{kg}$ de CAP por via intraperitoneal, ocasionada pelo antagonismo do ácido $\gamma$-aminobutírico (GABA), mediador químico em sinapses inibitórias do sistema nervoso central. A CAP pode causar alterações na colinesterase sanguínea e queratinização da laringe.

Tanto in vitro quanto in vivo os estudos de genotoxicidade apresentaram, em sua grande maioria, resultados negativos. Em contrapartida, poucos são aqueles que atribuem um possível efeito genotóxico à $\mathrm{CAP}$, considerada clastogênica em D. melanogaster (Vogel, 1989) e mutagênica em melanoblastos de camundongos (Fahrig, 1989).

A CAP pode também exercer algum efeito importante sobre o metabolismo. Sobre esta ótica, é preciso compreender melhor a toxicocinética da CAP e estabelecer seus reais efeitos sobre as vias metabólicas. As informações ainda são muito incipientes. E a quase ausência de estudos sobre esses aspectos não permite qualquer conclusão a respeito do tema. No que tange aos estudos sobre a reprodução, desenvolvimento pré-natal e carcinogenicidade, os resultados são claramente negativos. Ou seja, a CAP não provoca efeitos adversos sobre a reprodução e desenvolvimento na mesma cepa de ratos F344 e não induz câncer em camundongos $\mathrm{B} 6 \mathrm{C} 3 \mathrm{~F} 1 \mathrm{e}$ em ratos $\mathrm{F} 344$ de ambos os sexos. Baseado nos estudos de carcinogenicidade e desenvolvimento, a exposição prolongada à CAP pode, entretanto, promover redução do consumo alimentar e redução de peso corporal.

$\mathrm{O}$ valor da dose de referência de $0,5 \mathrm{mg} / \mathrm{kg}$ de peso corpóreo/dia ou $35 \mathrm{mg} /$ dia (indivíduo de $70 \mathrm{~kg}$ ) estabelecido pela EPA para ingestão oral de CAP foi determinado a partir do estudo de Serota et al. (1988). A União Européia (UE) e o Brasil (por força de harmonização) estabeleceram seus limites de migração específica de CAP para embalagens plásticas (Nylon 6) de alimentos com base no estudo desenvolvido pelo NTP em 1982. Visando a proteção da saúde humana, a UE recomenda um valor para ingestão dietética tolerada (IDT) de $0,25 \mathrm{mg} / \mathrm{kg}$ de peso corporal/ dia e um limite, para humanos de $60 \mathrm{~kg}$, igual a $15 \mathrm{mg} /$ $\mathrm{kg}$ de alimento.

Diante desse levantamento bibliográfico não parecem necessários estudos adicionais, excetuando-se, obviamente, aqueles relativos à natureza e a participação da CAP nas vias metabólicas ou endócrinas.

\section{REFERÊNCIAS BIBLIOGRÁFICAS}

ACGIH. American Conference of Governmental Industrial Hygienists. Documentation of the Threshold Limit Values and Biological Exposure Indices. Cincinnatti: American Conference of Governmental Industrial Hygienists, 1991. p. 208-211.

ACGIH. American Conference of Governmental Industrial Hygienists. Threshold Limit Values for Chemical Substances and Physical Agents. Cincinnati: American Conference of Governmental Industrial Hygienists, 2003. 224p.

AGUIRRE, A.; PEREZ, R.G.; ZUBIZARRETA, J; LANDA, N; DE GALDEANO, C.S.; PÉREZ, J.L.D. Allergic contact dermatitis from epsilon-caprolactam. Contact Derm., v.32, n.3, 174-175, 1995.

ALARIE, Y; STOCK, M.F. Report on caprolactam with respect to pulmonary sensitization and irritation potential in guinea pigs. Unpublished report for the Industrial Health Foundation, 1990. apud U. S. Environmental Protection Agency. Caprolactam (CASRN 105-60-2). Disponível em: $<$ http://www.epa.gov/iris/subst/0357.html $>$. Acesso em: 12 abr. 2008.

AMACHER, D.E.; TURNER, G.N. Tests for gene mutational activity in the L5178Y/TK assay system. In: ASHBY, J.; DE SERRES, F.J.; DRAPER, M.; ISHIDATE, M. JR.; MARGOLIN, B.H.; MATTER, B.E.; SHELBY, M.D., (Eds.). Progress in Mutation Research. New York: Elsevier Science Publishers, 1985. v.5, p.487-496.

ANGELOV, A. Gynecological morbidity in female workers engaged in the production of nitrogen fertilizers and caprolactam. Akush. Ginekol., v.27, n.1, p.51-54, 1988.

ASHBY, J.; SHELBY, M.D. Overview of the genetic toxicity of caprolactam and benzoin. Mutat. Res. Genet. Toxicol., v. 224, n.3, p.321-324, 1989.

BAKER, R.S.U.; BONIN, A.M. Tests with the Salmonella plate-incorporation assay. In: ASHBY, J.; DE SERRES, F.J.; DRAPER, M.; ISHIDATE, M. JR.; MARGOLIN, B.H.; MATTER, B.E.; SHELBY, M.D., (Eds.). Progress in Mutation Research. New York: Elsevier Science Publishers, 1985. v. 5, p. 177-180. 
BERMUDEZ,E.; OLIVER, T.S.; DELEHANTY,L.L. The induction of DNA-strand breaks and unscheduled DNA synthesis in F344 rat hepatocytes following in vivo administration of caprolactam and benzoin. Mutat. Res. Genet. Toxicol., v.224, n.3, p.361$364,1989$.

BILMAIER, D.J.; KNOWLDEN, N.F.; STIDHAM, D.W. Caprolactam: a study of current workers. Relatório não publicado da Allied-Signal Inc., 1992. apud U. S. Environmental Protection Agency. Caprolactam (CASRN 105-60-2). Disponível em: <http://www.epa.gov/iris/ subst/0357.html>. Acesso em: 12 Abr. 2008.

BRASIL. Resolução n 105 de 19 de maio de 1999. Aprova os regulamentos técnicos e disposições gerais para embalagens e equipamentos plásticos em contato com alimentos. Diário Oficial da República Federativa do Brasil, Brasília, 20 de maio de 1999. Disponível em: <http://e-legis.anvisa.gov.br/leisref/ public/showAct.php?id=19772\&word $=$ resolu $\%$ c3\%a7\%c3 \%a3o>. Acesso em: 01 Fev. 2009.

COMUNIDADE EUROPÉIA. Commission Directive 2002/72/ EC. 06 de agosto de 2002. Relating to plastic materials and articles intended to come into contact with foodstuffs. Off. J. Eur. Communities, L. 220, 2002, p.18-58.

EPA. U. S. Environmental Protection Agency. Caprolactam (CASRN 105-60-2). Disponível em: <http://www.epa.gov/iris/ subst/0357.html>. Acesso em: 12 Abr. 2008.

EPA. U.S. Environmental Protection Agency. OPPTS 870.2600: Skin Sensitization. S.1.: Environmental Protection Agency, 1998. Disponível em: <http://www.epa.gov/opptsfrs/ publications/OPPTS_Harmonized/870_Health_Effects_Test_ Guidelines/Series/870-2600.pdf>. Acesso em: 05 Fev. 2008.

EPA. U. S. Environmental Protection Agency. OPPTS 870.5915: In Vivo Sister Chromatid Exchange Assay. S.1.: Environmental Protection Agency, 1996. Disponível em: <http://www. epa.gov/opptsfrs/publications/OPPTS_Harmonized/870 Health_Effects_Test_Guidelines/Drafts/870-5915.pdf $>$. Acesso em: 05 Fev. 2008.

EUA. Estados Unidos da América. Caprolactam. Disponível em: $<$ http://toxnet.nlm.nih.gov/cgi-bin/sis/htmlgen?HSDB $>$. Acesso em: 25 Jan. 2008.

EUA. Estados Unidos da América. Carcinogenesis Biossay of Caprolactam (CAS n ${ }^{\circ}$ 105-60-2) in F344 Rats and B6C3F1 Mice (Feed Study). Washington: U.S. Department of Health and Human Services, 1982.129p.
FAHRIG, R. Possible recombinogenic effect of caprolactam in the mammalian spot test. Mutat. Res. Genet. Toxicol., v.224, n.3, p.373-375, 1989

FAHRIG, R.; KLAUSS, A. Positive effect of caprolactam in the mammalian spot test: an overview. Mutat. Res. Genet. Toxicol., v.224, n.3, p.377-378, 1989.

FERGUSON, W.S.; WHEELER, D.D. Caprolactam vapor exposures. Am. Ind. Hyg. Assoc. J., v.34, n.9, p.384-389, 1973.

FOX, M.; DELOW, G.F. Tests for mutagenic activity at the HGPRT locus in chinese hamster V79 cells in culture. In: ASHBY, J.; DE SERRES, F.J.; DRAPER, M.; ISHIDATE, M. JR., MARGOLIN, B.H.; MATTER, B.E.; SHELBY, M.D., (Eds.). Progress in Mutation Research. New York: Elsevier Science Publishers, 1985. v.5, p.517-523.

FRIEDMAN, M.A.; SALERNO, A.J. Influence of caprolactam on rat-liver tyrosine aminotransferase and tryptophan oxygenase. Food Cosmet. Toxicol., v.18, n.1, p.39-45, 1980

GAD, S.C.; ROBINSON, K.; SEROTA, D.G.; COLPEAN, B.R. Developmental toxicity studies of caprolactam in the rat and rabbit. J. Appl. Toxicol., v.7, n.5, p.317-326, 1987.

GLAUERT, H.P.; KENNAN, W.S.; SATTLER, G.L.; PITOT, H.C. Assays to measure the induction of unscheduled DNA synthesis in cultured hepatocytes. In: ASHBY, J.; DE SERRES, F.J.; DRAPER, M.; ISHIDATE, M. JR., MARGOLIN, B.H.; MATTER, B.E.; SHELBY, M.D., (Eds.). Progress in Mutation Research. New York: Elsevier Science Publishers, 1985. v.5, p.371-373.

GOLDBLATT, M.W.; FARQHHARSON, M.E.; BENNETT, G.; ASKEW, B.M. Epsilon-Caprolactam. Br. J. Ind. Med., v.11, n.1, p.1-10, 1954.

HOHENSEE, F. Pharmacologic and physiological action of E-caprolactam. Faserforsch. Textiltech., v.1, n.2, p.299, 1951.

IARC. International Agency for Research on Cancer. IARC Monographs on the evaluation of carcinogenic risks of chemicals to man: Caprolactam. Geneva: WHO, 1986. v.39, p.247-276. 
IARC. International Agency for Research on Cancer. IARC Monographs on the evaluation of carcinogenic risks to humans: Caprolactam. Geneva: WHO, 1999. v.71, p. 383.

ISHIDATE, M.; ODAGIRI, Y. Negative micronucleous tests on caprolactam and benzoin in ICR/JCL male mice. Mutat. Res. Genet. Toxicol., v.224, n.3, p.357-359, 1989.

JUNG, R.; ENGELHART, G.; HERBOLT, B.; JAECKH, R.; MUELLER, W. Collaborative study of mutagenicity with Salmonella typhimurium TA102. Mutat. Res. Genet. Toxicol., v.278, n.4, p.265-270, 1992.

KELMAN, G.R. Effects of human exposure to atmospheric epsiloncaprolactam. Hum. Toxicol., v.5, n.1, p.57-59, 1986.

KERR, D.I.B.; DENNIS, B.J.; BREUKER, E.L.M. Antagonism of GABA-mediated inhibition in the central nervous system by caprolactam derivates. Brain Res., v.110, n.2, p.413-416, 1976.

KOMA, A. The potential of nylon engineering plastics in Asia. Nylon 6 Promotional Group. UBE Industries, 2001. Disponível em: <http://www.npg-6.com/ filesystem/ upload/ Publications/Engineering\%20Plastics\%20in\%20 Asia.pdf $>$. Acesso em: 15 Maio 2007.

KRICHEVSKAYA, I.M. Biological effect of caprolactam and its sanitary-hygienic assessment as an atmospheric pollutant. Hyg. Sanit., v.33, n.1, p.24-30, 1968.

KRISTIANSEN, E.; SCOTT, D. Chromosomal analyses of human lymphocytes exposed in vitro. Mutat. Res. Genet. Toxicol., v.224, n.3, p.329-332, 1989.

KURODA, Y.; YOKOIYAMA, A.; KADA, T. Assays for the induction of mutations to 6-thioguanine resistance in chinese hamster V79 cells in culture. In: ASHBY, J.; DE SERRES, F.J.; DRAPER, M.; ISHIDATE, M. JR., MARGOLIN, B.H.; MATTER, B.E.; SHELBY, M.D., (Eds.). Progress in Mutation Research. New York: Elsevier Science Publishers, 1985. v.5, p.537-542.

KUROKI, T.; MUNAKATA, K. Assays for the induction of mutations to ouabain resistance in V79 chinese hamster cells in culture with cell or microsome-mediated metabolic activation. In: ASHBY, J.; DE SERRES, F.J.; DRAPER, M.; ISHIDATE, M. JR., MARGOLIN, B.H.; MATTER, B.E.; SHELBY, M.D., (Eds.). Progress in Mutation Research. New York: Elsevier Science Publishers, 1985. v.5, p.543545.
LIU, F.; BAO, Y.; ZHENG, C.L. The investigation on the effect of caprolactam on the sexual functions of a female worker. $J$. China Work Health Occup. Dis., v. 6, n.4, p.201-203, 1988.

LOMONOVA, G.V. Toxicity of caprolactam. Gig. Tr. Prof. Zabol., v.10, n.1, p.54-57, 1966.

MARTYNOVA, A.P.; LOTIS, V.M.; KHADZHIEVA, E.D.; GAIDOVA, E.S. Occupational hygiene of women engaged in the production of capron fiber. Gig. Tr. Prof. Zabol., v.16, n.11, p. 9-13, 1972.

MCFEE, A.F; LOWE, K.W. Caprolactam and benzoin: tests for induction of chromosome aberrations and SCEs in mouse bone marrow. Mutat. Res. Genet. Toxicol., v.224, n.3, p.347-350, 1989.

MOLECULAR SIMULATIONS INC. Web Lab Viewer Pro versão 3.1. San Diego: s.n., 1998. 1 CD-ROM.

MUELLER, W.; ENGELHART, G.; HERBOLT, B.; JAECKH, R.; JUNG, R. Evaluation of mutagenicity testing with Salmonella tiphimurium TA102 in three different laboratories. Environmental Health Perspectives, v.101, supl.3, p.33-36, 1993

NADEZHDINA, L.D.; TALAKINA, E.I. Status of the menstrual and child-bearing function of pregnant female workers in the caprolactam industry. Gig. Tr. Prof. Zabol., v. 15, n.11, p. 43-44, 1971.

NIOSH. National Institute of Ocupational Safety and Health. Pocket Guide to Chemical Hazardous. Disponível em: $<$ http://www.cdc.gov/niosh/npg/npgd0097.html>. Acesso em: 17 Dez. 2007.

NORPPA, H.; JARVENTAUS, H. Induction of chromosome aberrations and sister-chromatid exchanges by caprolactam in vitro. Mutat. Res. Genet. Toxicol., v. 224, n.3, p.333-337, 1989.

OBERLY, T.Y.; BEWSEY, B.J.; PROBST, G.S. Tests for the induction of forward mutations at the thymidine-kinase locus of L5178Y mouse lymphoma cells in culture. In: ASHBY, J.; DE SERRES, F.J.; DRAPER, M.; ISHIDATE, M. JR., MARGOLIN, B.H.; MATTER, B.E.; SHELBY, M.D., (Eds.). Progress in Mutation Research. New York: Elsevier Science Publishers, 1985. v.5, p.569-582. 
OECD. Organization for Economic Cooperation and Development. SIDS Initial Assessment Report for $12^{\circ}$ SIAM: $\varepsilon$-Caprolactam. Paris: United Nations Environment Programme Publications, 2001. p.24-44.

OECD. Organization for Economic Cooperation and Development. Test $N^{\circ}$ 414: Prenatal Development Toxicity Study. S.1.: OECD Publications, 2001. Disponível em: $<$ http://lysander. sourceoecd.org/vl=13333787/cl=18/nw=1/rpsv/cgi-bin/ fulltextew.pl?prpsv=/ij/oecdjournals/1607310x/v1n4/s15/ p1.idx>. Acesso em: 15 Dez. 2007.

OECD. Organization for Economic Cooperation and Development. Test $N^{\circ}$ 415: One-Generation Reproduction Toxicity Study. S.1.: OECD Publications, 1983. Disponível em: <http:// lysander.sourceoecd.org/vl=13333787/cl=18/nw=1/rpsv/cgibin/fulltextew.pl?prpsv=/ij/oecdjournals/1607310x/v1n4/s16/ p1.idx>. Acesso em: 15 Dez. 2007.

OECD. Organization for Economic Cooperation and Development. Test $N^{\circ}$ 416: Two-Generation Reproduction Toxicity. S.1.: OECD Publications, 2001. Disponível em: <http://oberon. sourceoecd.org/vl=794835/cl=24/nw=1/rpsv/cgi-bin $/$ fulltextew.pl?prpsv=/ij/oecdjournals/1607310x/v1n4/s17/ p1.idx>. Acesso em: 15 Dez. 2007.

OECD. Organization for Economic Cooperation and Development. Test $N^{\circ}$ 451: Carcinogenicity Studies. S.1.: OECD Publications, 1981. Disponível em: <http://lysander. sourceoecd.org/vl=12086647/cl=11/nw=1/rpsv/cgi-bin/ fulltextew.pl?prpsv=/ij/oecdjournals/1607310x/v1n4/s36/ p1.idx>. Acesso em: 15 Dez. 2007.

OECD. Organization for Economic Cooperation and Development. Test $N^{\circ}$ 471: Bacterial Reverse Mutation Test. S.1.: OECD Publications, 1997. Disponível em: <http://lysander. sourceoecd.org/vl=12086647/cl=11/nw=1/rpsv/cgi-bin/ fulltextew.pl?prpsv=/ij/oecdjournals/1607310x/v1n4/s39/ p1.idx>. Acesso em: 15 Dez. 2007.

OECD. Organization for Economic Cooperation and Development. Test $N^{\circ}$ 473: In vitro Mammalian Chromosome Aberration Test. S.1.: OECD Publications, 1997. Disponível em: < http:// lysander.sourceoecd.org/vl=12086647/cl=11/nw=1/rpsv/cgibin/fulltextew.pl?prpsv=/ij/oecdjournals/1607310x/v1n4/s40/ p1.idx >. Acesso em: 15 Dez. 2007.

OECD. Organization for Economic Cooperation and Development. Test $N^{\circ}$ 474: Mammalian Erythrocyte Micronucleus Test. S.1.: OECD Publications, 1997. Disponível em: <http://oberon. sourceoecd.org/vl=794835/cl=24/nw=1/rpsv/cgi-bin/ fulltextew.pl?prpsv=/ij/oecdjournals/1607310x/v1n4/s41/ p1.idx>. Acesso em: 15 Dez. 2007.
OECD. Organization for Economic Cooperation and Development. Test $N^{\circ}$ 475: Mammalian Bone Marrow Chromosome Aberration Test. S.1.: OECD Publications, 1997. Disponível em: $<$ http://oberon.sourceoecd.org/vl=794835/cl=24/nw=1/ rpsv/cgibin/fulltextew.pl?prpsv=/ij/oecdjournals/1607310x/ v1n4/s42/p1.idx>. Acesso em: 15 Dez. 2007.

OECD. Organization for Economic Cooperation and Development. Test $N^{\circ}$ 476: In vitro Mammalian Cell Gene Mutation Test. S.1.: OECD Publications, 1997. Disponível em: <http:// lysander.sourceoecd.org/vl=12086647/cl=11/nw=1/rpsv/ cgi-bin/fulltextew.pl?prpsv=/ij/oecdjournals/1607310x/v1n4/ s43/p1.idx>. Acesso em: 15 Dez. 2007.

OECD. Organization for Economic Cooperation and Development. Test $N^{\circ}$ 477: Sex-Linked Recessive Lethal Test in Drosophila melanogaster. S.1.: OECD Publications, 1984. Disponível em: $<$ http://lysander.sourceoecd.org/vl=12086647/cl=11/nw=1/ rpsv/cgi-bin/fulltextew.pl?prpsv=/ij/oecdjournals/1607310x/ v1n4/s44/p1.idx>. Acesso em: 15 Dez. 2007.

OECD. Organization for Economic Cooperation and Development. Test $N^{\circ}$ 479: In vitro Sister Chromatid Exchange Assay in Mammalian Cells. S.1.: OECD Publications, 1986. Disponível em: $<$ http://oberon. sourceoecd.org/vl=794835/cl=24/nw=1/ rpsv/cgi-bin/fulltextew.pl?prpsv=/ij/oecdjournals/1607310x/ v1n4/s46/p1.idx>. Acesso em: 15 Dez. 2007.

OECD. Organization for Economic Cooperation and Development. Test $N^{\circ}$ 482: DNA Damage and Repair, Unscheduled DNA Synthesis in Mammalian Cells in vitro. S.1.: OECD Publications, 1986. Disponível em: http://lysander.sourceoecd. $\mathrm{org} / \mathrm{vl}=12086647 / \mathrm{cl}=11 / \mathrm{nw}=1 / \mathrm{rpsv} / \mathrm{cgi}$-bin $/$ fulltextew. $\mathrm{pl}$ ?prpsv=/ij/oecdjournals/1607310x/v1n4/s49/p1.idx >.Acesso em: 15 Dez. 2007.

OECD. Organization for Economic Cooperation and Development. Test $N^{\circ}$ 484: Mouse Spot Test. S.1.: OECD Publications, 1986. Disponível em: <http://lysander.sourceoecd.org/ $\mathrm{vl}=12086647 / \mathrm{cl}=11 / \mathrm{nw}=1 / \mathrm{rpsv} /$ cgi-bin/fulltextew.pl?prpsv=/ ij/oecdjournals/1607310x/v1n4/s51/p1.idx>. Acesso em: 15 Dez. 2007.

OECD. Organization for Economic Cooperation and Development. Test $N^{\circ}$ 486: Unscheduled DNA Synthesis (UDS) Test with Mammalian Liver Cells. S.1.: OECD Publications, 1997. Disponível em: <http://oberon.sourceoecd.org/vl=794835/ $\mathrm{cl}=24 / \mathrm{nw}=1 / \mathrm{rpsv} / \mathrm{cgi}$-bin/fulltextew.pl?prpsv $=/ \mathrm{ij} /$ oecdjournals/1607310x/v1n4/s53/p1.idx>. Acesso em: 15 Dez. 2007. 
PARODI, S.; ABELMOSCHI, M.L.; BALBI, C.; ANGELI, M.T.; PALA, M.; RUSSO, P. Induction of chromosome aberrations and sister-chromatid exchanges by caprolactam in vitro. Mutat. Res. Genet. Toxicol., v.224, n.3, p.379-384, 1989.

PATEL, M.B. Study of lung functions in caprolactam workers. Indian J. Ind. Med., v.36, n.2, p.76-81, 1990.

PETROV, N.V. Health status of women working in the chemical fiber industry based on data from medical examinations. Vrach. Del., v.10, n.1, p.145-148, 1975.

REINHOLD, R.W.; HOFFMAN, G.M.; HENRY, F.B.; RINEHART, W.E.; RUSCH, G.M.; PAROD, R.J.; KAYSER, M. Subchronic inhalation toxicity study of caprolactam (with a 4 week recovery) in the rat via wholebody exposures. Toxicol. Sci., v.44, n.2, p.197-205, 1998.

REXROAT, M.A.; PROBST, G.S. Mutation tests with Salmonella using the plate-incorporation assay. In: ASHBY, J.; DE SERRES, F. J.; DRAPER, M.; ISHIDATE, M. JR., MARGOLIN, B.H.; MATTER, B.E.; SHELBY, M.D., (Eds.). Progress in Mutation Research. New York: Elsevier Science Publishers, 1985. v.5, p.201-212.

SARANTÓPOULOS, C.I.G.L.; OLIVEIRA, L.M.; PADULA, M.; COLTRO, L;ALVES, R.M.V.; GARCIA, E.E.C. Embalagens Plásticas Flexíveis: Principais polímeros e avaliação de propriedades. Campinas: Centro de Tecnologia de embalagem (CETEA) / Instituto de Tecnologia de Alimentos (ITAL), 2002. $267 \mathrm{p}$.

SEROTA, C.G.; HOBERMAN, A.M.; GAD, S.C. Three generation reproduction study with caprolactam in rats. J. Appl. Toxicol., v.84, n.4, p.285-293, 1988.

SHELDON, T. An evaluation of caprolactam and benzoin in the mouse micronucleus test. Mutat. Res. Genet. Toxicol., v.224, n.3, p.351-355, 1989a.
SHELDON, T. Chromosomal damage induced by caprolactam in human lymphocytes. Mutat. Res. Genet. Toxicol., v.224, n.3, p. 325-327, 1989 b.

SITTIG, M. Handbook of toxic and hazardous chemicals and carcinogens. 2. ed. New Jersey: Noyes Publications, 1985. p.179-180.

TUMA, S.N.; ORSON, F.; FOSSELA, F. V. Seizures and dermatitis after exposure to caprolactam. Arch. Intern. Med., v.141, n.11, p.1544-1545, 1981.

UNEP. United Nations Environment Programme. Scientific Reviews of Soviet Literature on Toxicity and Hazards of Chemicals. Caprolactam. Moscou: UNEP Publications, 1985. 19p.

VOGEL, E.W. Caprolactam induces genetic alterations in early germ cell stages and in somatic tissue of $D$. melanogaster. Mutat. Res. Genet. Toxicol., v.224, n.3, p.339-342, 1989.

WORKING, P.K. Assessment of unscheduled DNA synthesis in Fischer F344 rat pachytene spermatocytes exposed to caprolactam or benzoin in vivo. Mutat. Res. Genet. Toxicol., v.224, n.3, p.365-368, 1989.

ZDZIENICKA, M.Z.; SIMMONS, J.W. Assays for the induction of mutations to 6-thioguanine and ouabain resistance in chinese hamster ovary $(\mathrm{CHO})$ cells in culture. In: ASHBY, J.; DE SERRES, F.J.; DRAPER, M.; ISHIDATE, M. JR., MARGOLIN, B.H.; MATTER, B.E.; SHELBY, M.D., (Eds.). Progress in Mutation Research. New York: Elsevier Science Publishers, 1985. v.5, p.583-586.

ZEIGER, E.; HAWORTH, S. Tests with a preincubation modification of the Salmonella / Microsome assay. In: ASHBY, J.; DE SERRES, F.J.; DRAPER, M.; ISHIDATE, M. JR., MARGOLIN, B.H.; MATTER, B.E.; SHELBY, M.D., (Eds.). Progress in Mutation Research. New York: Elsevier Science Publishers, 1985. v.5, p.187-199.

Recebido para publicação em 08 de maio de 2008. Aceito para publicação em 12 de setembro de 2008. 